\title{
Um amontoado de versos: o cordel nas mídias digitais em tempos de pandemia
}

\author{
A handling of verses: the cordel in digital media in pandemic times

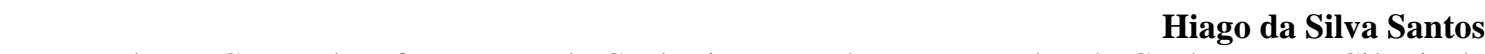 \\ Mestrando em Gestão da Informação e do Conhecimento pelo Programa de Pós-Graduação em Ciência da \\ Informação da Universidade Federal de Sergipe - UFS, Brasil. \\ E-mail: $\underline{\text { hsto98@live.com }}$ \\ Martha Suzana Cabral Nunes \\ Doutora em Ciência da Informação pela Universidade Federal da Bahia - UFBA, Brasil. \\ Professora adjunta do Departamento de Ciência da Informação da Universidade Federal de Sergipe, Brasil. \\ E-mail: marthasuzana@ hotmail.com \\ https://orcid.org/0000-0002-0587-5354 \\ Pablo Boaventura Sales Paixão \\ Doutor em Ciência da Informação pela Universidade Complutense de Madri, com título revalidado pela \\ Universidade de Brasília - UnB, Brasil. \\ Professor adjunto do Programa de Pós-Graduação em Ciência da Informação da Universidade Federal de \\ Sergipe, Brasil. \\ E-mail: pabloboaventura1@ hotmail.com
}

\section{Resumo}

Do folheto ao ciberespaço, a literatura de cordel tem ganhado força e espaço em diferentes mídias sociais, em especial, no atual momento de pandemia do novo coronavírus. O presente estudo busca identificar a motivação da cordelista sergipana Claudia Emilly Silva Barreto para atuar no meio digital, conhecendo suas principais estratégias de marketing digital, bem como, analisando como a utilização das mídias digitais tem influenciado em seu trabalho durante a pandemia e as principais dificuldades que enfrenta nesse contexto. $\mathrm{O}$ intuito é responder à questão: Como tem sido a atuação da cordelista do perfil "Um amontoado de versos" no contexto da era das mídias digitais no atual momento de pandemia por Covid19? A metodologia utiliza uma abordagem qualitativa, por estudo de caso, sendo as análises feitas mediante Análise de Conteúdo de Laurence Bardin. Os resultados da pesquisa apontam forte relação na utilização das mídias digitais pela cordelista, motivada pela situação de quarentena decorrente da pandemia instalada no país. Sua principal mídia social é o Instagram, por onde busca e é encontrada por outros artistas que desejam fazer parceria. Dentre as dificuldades encontradas na atuação no meio digital está a falta de equipamentos de qualidade para produção de seu conteúdo, sendo que a pandemia não influenciou negativamente em seu trabalho.

Palavras-chave: Literatura de cordel. Mídias digitais. Pandemia.

\begin{abstract}
From leaflet to cyberspace, cordel literature has gained strength and space in different social media, especially in the current pandemic moment of the new coronavirus. The present study seeks to identify the motivation of the sergipana cordelista Claudia Emilly Silva Barreto to work in the digital environment, knowing her main digital marketing strategies, as well as analyzing how the use of digital media has influenced her work during the pandemic and the main difficulties that face in that context. The aim is to answer the question: How has the cordelist with the profile "A heap of verses" been doing in the context of the era of digital media in the current pandemic moment by Covid19? The methodology uses a qualitative approach, by case study, and the analyzes are made by Laurence Bardin's Content Analysis. The survey results point to a strong relationship in the use of digital media by the cordelista, motivated by the quarantine situation resulting from the pandemic installed in the country. His main social media is Instagram, where he searches and is found by other artists who wish to partner. Among the difficulties encountered in working in the digital environment is the lack of quality equipment for the production of its content, and the pandemic did not have a negative influence on their work.
\end{abstract}

Keywords: Literature of twine. Digital media. Pandemic.

InCID: R. Ci. Inf. e Doc., Ribeirão Preto, v. 12, n. 2, p. 239-260, set. 2021./fev. 2022. 


\section{Introdução}

As mudanças advindas com os avanços tecnológicos fizeram surgir diversas formas de tratamento da informação, resultando em mudanças culturais que possibilitaram o acesso à informação em tempo real e em maior quantidade, uma vez que a maior parte da informação que era registrada em papel passou a ser produzida em formato digital (VALENTIM, 2010). A essas transformações, Henry Jenkins (2009) dá o nome de Cultura da Convergência, a partir da qual há diversos formatos de mídia coexistentes, onde seus produtores e consumidores exercem poder entre si, não havendo mais a figura do consumidor espectador, mas um protagonista, que opta por experiências e migra, conforme seu desejo, entre os meios de comunicação e circulação de conteúdo dos múltiplos mercados midiáticos.

Tais mudanças têm causado impacto sobre a forma como é transmitida a cultura pelas manifestações artísticas populares. Segundo Trigueiro (2004, p. 2), na década de 1970 começou a se intensificar no Brasil um fenômeno de espetacularização das culturas populares, envolvendo "processos de apropriação e incorporação das manifestações culturais populares pela mídia", em que houve a apropriação "das novas tecnologias para reinventarem os seus produtos culturais". A esses produtos o autor dá o nome de folkmidiáticos. Assim, o que antes, segundo Betella e Cação (2016), era repassado de geração a geração com viés principalmente oral, hoje tem estado cada vez mais presente nas mídias modernas.

Para Porfírio (2021), é da interação do povo que surge a cultura popular, expressa de forma autêntica pelos esforços dos artistas, a exemplo da literatura de cordel nordestina, objeto deste estudo, que tem a característica comum de ser lembrado e revisitado. Segundo Jares (2010), o cordel representa a preservação da memória histórica e coletiva de um povo e é transmitido de geração em geração como tradição cultural expressa por meio da oralidade, responsável pela formação da identidade desse povo. Essa identidade se firma na literatura popular como uma das muitas expressões artístico-culturais brasileiras e referência na representação da cultura nordestina. Segundo Nobre (2018), acredita-se que a literatura de cordel nordestina surgiu com os cantadores que se apresentavam nas cidades levando histórias em forma de versos para falar dos mais diversos assuntos como política e histórias do cotidiano. O termo era usado já no século XX como 'folheto', que tinha o objetivo de ser barato e popular.

Tal fato contraria, segundo Ria Lemaire ([201-], p. 6) o que ela chama de "discurso acadêmico, scriptocêntrico, das ciências humanas" repetido pelos alunos dos cursos de Letras, 
ao definir o mundo da cantoria e do folheto de cordel nordestinos como um "tesouro arcaico, primitivo, inculto e imutável, banalmente repetitivo e em vias de extinção". Existe, portanto, uma dicotomia, segundo a autora, imposta pelos intelectuais que é intransponível no discurso "científico", havendo uma oposição entre dois mundos, o "inculto das tradições orais, locais e regionais" e o "mundo culto, erudito da cultura oficial, nacional, com o objetivo de sobressalientar a superioridade deste e do seu conhecimento livresco que ele transmite às novas gerações através do ensino formal moderno."

Diante dessa dicotomia, o presente estudo lança mão do cordel como cultura popular ou poesia popular, abordando-o sob o ponto de vista de sua contribuição como fonte de informação e comunicação, uma vez que, segundo Ria Lemaire ([201-], p. 6) o folheto de cordel nordestino precisa ser tratado como "capítulo da história mundial das tecnologias da informação e da comunicação" o que, segundo a autora,

\begin{abstract}
permitirá elaborar no Brasil do século XXI uma nova visão desse fenômeno editorial que criaram os poetas-cantadores-violeiros, quando chegou em terras nordestinas, no final do século XIX, a tipografia com todas as suas novas possibilidades de produção, transmissão, recepção/divulgação e salvaguarda do conhecimento (LEMAIRE, [201], p. 6)
\end{abstract}

Sendo assim, dada sua importância para a formação de identidade e memória cultural nordestina (BRASILEIRO; SILVEIRA, 2013); como patrimônio cultural nacional (IUMATTI, 2019); fonte de informação (NASCIMENTO; SANTOS, 2015); ferramenta para didática na educação (MARIANO; SANTOS, 2019); mídia alternativa na prevenção ao novo Coronavírus (ALBUQUERQUE et al., 2020); como meio de reflexão moral e denúncia social (LIMA, 2020), de transformação do sujeito, do lugar e de seu povo (PAZ; BEZERRA JÚNIOR, 2020), o cordel vai além da função educativa, exercendo "função política e social, como meio alternativo de comunicação que integra o sertão nordestino ao resto do Brasil” (JARES, 2010, p. 12).

Sendo o cordel desde sempre uma mídia (FREITAS; SOUZA, 2020), os avanços nas Tecnologias da Informação e Comunicação (TIC) têm causado impactos no decorrer dos anos sobre sua produção e disseminação, principalmente quanto ao seu formato de apresentação. Esses avanços, segundo Castells (2002), se intensificaram a partir da década de 1970, com um novo sistema tecnológico capaz de conectar o mundo por meio de redes globais de comunicação mediadas por computadores capazes de gerar comunidades virtuais que se utilizam de uma linguagem digital para geração, armazenamento, recuperação, processamento e transmissão da informação. 
Uma vez que "os gêneros do discurso são sensíveis a mudanças na prática social de que participam" (RESENDE, 2006, p. 44), o cordel sobrevive em meio a essa sociedade conectada que tem o poder de escolher, dentre inúmeras opções, aquilo que mais lhe conquista a atenção. O cordelista que não ignora essas questões está mais bem preparado para conseguir despertar o interesse por essa expressão artístico-cultural tão importante à sociedade.

Cláudia Emilly Silva Barreto, cordelista da cidade de Nossa Senhora da Glória, Estado de Sergipe, parece não ignorar o novo contexto em que se insere a literatura de cordel. A artista popular do sertão sergipano tem atuado nas principais mídias digitais desde o ano de 2017, com o perfil nomeado de 'Um Amontoado de Versos', onde faz publicações de suas produções de cordel e vem se atualizando junto às mudanças ocorridas no comportamento do público e das ferramentas disponíveis na internet, como forma de manter valorizada a cultura do cordel.

Durante muito tempo a mulher esteve ausente das produções de folhetos. A primeira mulher conhecida como autora de cordel publicado usou um pseudônimo masculino em 1938 e, somente na década de 1970 é que elas conseguiram se manifestar com autonomia. Hoje, a cordelista Emilly Barreto representa as mulheres que, por meio da escrita do cordel, "denunciam uma realidade social e anunciam perspectivas de vida". Sejam elas professoras, psicólogas, donas de casa ou advogadas, ganham seu espaço na literatura de cordel, consolidando suas identidades autorais, deixando "fluir sua poeticidade e, através dela, demonstram seus sentimentos, aspirações e visões de mundo" (QUEIROZ, 2006, p. 6).

A cordelista de 20 anos tem papel fundamental na representação da cultura sergipana e na popularização do cordel no Estado. Cursando Letras Português na Universidade Federal de Sergipe (UFS), está envolvida com o Programa Institucional de Bolsas de Iniciação à Docência (PIBID), por meio do qual, tem levado o cordel à sala de aula como gênero textual, utilizandoo para a absorção do conteúdo por parte de crianças do $6^{\circ}$ ao $9^{\circ}$ ano. Na instituição, ainda faz parte do grupo de pesquisa "GELIC - Estudos de Literatura e de Cultura" do Programa Institucional de Bolsas de Iniciação Científica (PIBIC) onde desenvolve, em parceria com a Universidade de Paris, a pesquisa "O mapeamento de cordéis épicos sergipanos".

A artista tem ganhado notoriedade no ciberespaço ${ }^{1}$, com sua atuação nas mídias digitais - plataformas de comunicação do ciberespaço que torna possível a socialização em rede, tais

${ }^{1}$ Pierre Levy (1999, p. 22) define ciberespaço (ou rede) como "o novo meio de comunicação que surge da interconexão mundial dos computadores", que depende de infraestrutura digital e das pessoas que o alimentam com informações. 
como sites, Facebook e Instagram - ao passo que tem tido uma das atuações artísticas mais expressivas do Estado na atualidade. Tal atuação foi intensificada com a pandemia causada pelo novo coronavírus (SARS-CoV-2), causador da doença intitulada Covid-19, resultando em medidas restritivas do governo do Estado, como distanciamento social e proibição de manifestações públicas.

Com isso, em entrevista à Agência Brasil (VERDÉLIO, 2020), Angel Gurría, secretáriogeral da Organização para a Cooperação e Desenvolvimento Econômico (OCDE), afirma que a pandemia motivou a entrada de milhões de pessoas na era digital, uma vez que surgiu a necessidade de que o trabalho e os estudos fossem realizados remotamente, por vias digitais, com o intuito de evitar o contato social e a propagação do coronavírus. Segundo o secretáriogeral, o aumento no tráfego da internet foi de $50 \%$ em vários países, incluindo o Brasil, desde o início de 2020 (VERDÉLIO, 2020).

Vale ressaltar que, mesmo já tendo havido outras pandemias, o mundo nunca esteve tão conectado num momento pandêmico. Segundo Santaella (2001, p. 1), é "como se o mundo inteiro estivesse, de repente, virado digital", onde todas as mídias convergem para a transmissão nesse formato e sons, imagens, vídeos e textos podem ser lidos na linguagem computacional. Esta é a nova era da então consagrada comunicação, que desde a entrada do século XXI é considerada onipresente, na qual milhões de pessoas estão conectadas, mais próximas, em um mundo virtual.

Diante do exposto, o presente artigo traz a seguinte questão: Como tem sido a atuação da cordelista do perfil nas mídias sociais "Um amontoado de versos" no contexto da era das mídias sociais em meio à pandemia por Covid-19? Para responder ao questionamento, o presente estudo busca identificar a motivação da cordelista para atuar no meio digital, conhecendo suas principais estratégias de marketing digital em tempos de pandemia, bem como, analisar como a utilização das novas mídias tem influenciado em seu trabalho e as principais dificuldades que tem enfrentado nesse contexto. 


\section{Um movimento de apropriação, do folheto ao virtual}

Registrado no ano de 2018 como patrimônio cultural do Brasil pelo Instituto do Patrimônio Histórico e Artístico Nacional (IPHAN), o cordel teve seu reconhecimento social marcado por processos de apropriação de diversos meios de comunicação (MELO, 2019). Ao final do século XIX emergiam três processos que possibilitaram a consolidação da cultura impressa do cordel: a já estabelecida poética cantada, a produção de folhetos pelas máquinas tipográficas no Nordeste e, por último, a apropriação das Tecnologias da Informação e Comunicação (TIC) pelos emergentes cordelistas. A partir disso, surgiu um "extraordinário sistema de produção e circulação de folhetos, divulgados a partir de um mercado proveniente das feiras existentes nas cidades interioranas do Nordeste" (SANTOS, 2010, p. 3).

Tamanha apreciação da literatura de cordel passou, a partir do final do século XIX, pelos processos de constituição simbólica nacional, pela formação de coleções, arquivos e centros de pesquisa, e pela atuação dos grupos referenciais dos poetas e do IPHAN no processo de inventário, com intuito de legitimá-la como gênero da literatura brasileira e consagrá-la como patrimônio cultural (IUMATTI, 2019; MELO, 2019).

Nas primeiras décadas do século XX, sua oralidade marcante ganhava cada vez mais importância ao receber o suporte do folheto impresso que ajudou no registro das obras, tornando-se uma forma de expressão economicamente promissora, ainda que, por algumas décadas, tenha tido sua comercialização criminalizada, considerada como contravenção, quando muitos editores e poetas foram perseguidos e presos, acusados de comércio ilegal de folhetos de cordel. Além da coerção do Estado, conhecida como "rapa", muitos críticos literários consideravam os poetas como pessoas sem pudor e prejudiciais à mocidade (MELO, 2019).

Mesmo assim, o cordel foi se consolidando por meio do registro e da publicação. A partir de 1957, a Fundação Casa de Rui Barbosa (FCRB) iniciou seus estudos e pesquisas sobre o cordel, organizando um plano de divulgação do gênero. Em 1961, a Campanha de Defesa do Folclore Brasileiro começou seu acervo de literatura de cordel chegando a possuir hoje cerca de 7 mil títulos que se encontram no Centro Nacional de Folclore e Cultura Popular (CNFCP), disponíveis na internet (MELO, 2019).

A partir da expressiva relevância que o cordel foi construindo ao passar dos anos, em 2010, a Academia Brasileira de Literatura de Cordel encaminhou o pedido de registro da 
literatura de cordel como patrimônio cultural do Brasil pelo IPHAN e, a partir de 2012, como forma de salvaguarda, "o Arquivo do Instituto de Estudos Brasileiros da USP sistematizou as informações contidas na maior parte dos acervos de literatura de cordel existentes no país e no exterior", disponibilizadas no Portal de Literatura de Cordel (MELO, 2019, p. 252).

É perceptível que, no decorrer da história, poetas e movimentos intelectuais seguiram em busca pelo reconhecimento do cordel e de sua salvaguarda, como garantia de ser expressa nas gerações futuras, seja na sua monumentalização ou na sua divulgação. Segundo Melo (2019), na obra Cantadores de 1921, o folclorista Leonardo Mota se apresenta como interlocutor na relação entre sertão e civilização, com o intuito de proteger a poesia popular do esquecimento e afirma que o que ameaçava esse costume do sertanejo eram a modernização e a urbanização.

No entanto, a urbanização, o aumento dos níveis de escolaridade, o desenvolvimento e popularização das TIC e o uso da internet na disseminação dessa forma de expressão e de seus agentes, ajudaram a aumentar o alcance de público, passando ainda, a ser produzido em ambiente letrado. Antes considerado marginalizado, hoje reconhecido e institucionalizado, o cordel alcança um de seus melhores momentos (DESTRI, 2019; FREITAS; SOUZA, 2020; MELO, 2019).

Tendo acompanhado o desenvolvimento e avanços tecnológicos em todos esses anos, o folheto chega ao ciberespaço não sob o temor de entrar em desuso, mas se apropriando das TIC e de suas respectivas linguagens para a publicização das obras. Para que seja possível a comunicação, faz-se necessário o estudo da relação existente entre o cordel e as mídias digitais. Para Freitas e Souza (2020, p. 163-165) "o cordel sempre teve uma veia midiática, o que o coloca em consonância com o atual contexto multimídia do ciberespaço”. Para os autores, o cordel disponibilizado nas mídias possui aspectos semelhantes a outros gêneros virtuais como os memes, que permitem "a quebra de expectativa, a justaposição, a repetição, e a ressignificação", utilizando-se de uma "linguagem irreverente, largamente praticada na Internet", permitindo, ainda, o apelo popular e a proximidade com a realidade dos leitores.

As mídias digitais permitiram, segundo Freitas e Souza (2020), que a oralidade do cordel fosse resgatada, já que, ainda que disponibilizado em folheto, o cordel foi feito para ser recitado, assim como é feito nos diversos formatos permitidos pelas mídias digitais, mantendo-o apto a permanecer na rede, com sua rica estética e memória. A oralidade midiatizada é apresentada por Zamthor (1985) como aquela que vai além da oralidade da voz ou daquela que advém da 
escrita. Esta surge pela interferência dos diversos meios eletrônicos de difusão da informação e comunicação, conhecidos popularmente como mídias.

Assim, nesse contexto de oralidade midiatizada, o cordel e seus poetas encontram oportunidades de se estabelecerem e ganharem mais visibilidade diante da multimodalidade das mídias digitais, em “cibertexto, imagem, áudio, vídeo, xilogravuras animadas [desenho, antes entalhado em madeira, hoje produzido digitalmente com visual de relevo], corpo em movimento [...] disponível ao público a qualquer tempo e em quase todos os lugares". O caráter interativo das mídias digitais dá a liberdade para que "o público responda, opine, assinale que gostou [ou não] [...], compartilhe, copie a mídia em questão e a altere [...], participando da produção como nunca fora possível antes" (FONSECA, 2016; FREITAS; SOUZA, 2020, p. 171).

Do ponto de vista da atuação dos poetas no ambiente virtual, cabe ressaltar que alguns deles se tornaram fenômenos artístico-midiáticos ao transmitirem seus poemas em plataformas digitais como YouTube, Instagram e Facebook. Exemplo desse fenômeno é o perfil no YouTube de Jessier Quirino, que conta com mais de 87 mil seguidores. Já o cordelista Bráulio Bessa, tornou-se fenômeno midiático a partir de 2014, quando seus vídeos recitando os poemas populares nordestinos caíram no gosto popular, principalmente, por trazerem poemas que abordam a conduta dos brasileiros nos assuntos políticos emergentes à época. Na televisão, chegou a ser reconhecido como o "Artista mais assistido das mídias sociais da Rede Globo em 2017" (BESSA, 2020 apud FREITAS; SOUZA, 2020).

Tal representatividade fortalece ideais de reconhecimento e sobrevivência do cordel, favorecendo sua promoção diante de novos gêneros literários e realidades que surgem. $\mathrm{O}$ sucesso dos cordelistas se deve, em parte, ao formato das produções disponibilizadas na rede, onde a expressão corporal dá sentido ao poema. A recitação de versos e as expressões corporais possibilitadas pelo suporte audiovisual, aspectos que não são possíveis ao folheto, torna o vídeo "um meio de rever e ressignificar elementos enunciativos, situacionais, expressivos e performáticos, inerentes à oralidade" (FREITAS; SOUZA, 2020, p. 16). 


\subsection{A literatura de cordel em tempos de pandemia}

O cordel busca se estabelecer em meio ao atual estado de pandemia causado pelo coronavírus. Não obstante, o cordel é muito utilizado como meio de conscientização sobre a doença. Em Ipiranga do Piauí, a professora Lecy Ramos criou, junto a seus alunos, cordéis sobre os desafios enfrentados durante os estudos sem as aulas presenciais. Intitulado "Nosso cordel: Tempo de Pandemia", o livreto traz relatos da rotina de estudos nas aulas à distância e cede espaço para homenagear os profissionais de saúde que têm trabalhado na linha de frente no tratamento dos casos da doença (COSTA, 2020) como apresentado na Figura 1.

Figura 1 - Recortes de quatro cordéis da Unidade Escolar Dom Joaquim Rufino do Rêgo

\begin{tabular}{|c|c|c|c|}
\hline Foi nos meados de junho & O Canal Educação & Os profissionais da saúde & Lave bem as mãos, \\
\hline Os alunos desmotivados & Logo entrou em ação & Foram os mais afetados & Evite se contaminar \\
\hline Procurava uma forma para os despertar & Fazendo a transformação & Até suas vidas arriscaram & O virus é sério \\
\hline Pensei logo num cordel & Da nossa Educação & Para dos contaminados cuidar & Se não se cuidar \\
\hline Que a Flávia estava a ensinar & Nada está sendo fácil & $\begin{array}{l}\text { Eles são força e dedicação } \\
\text { Dedicam amor e muita atenção }\end{array}$ & Não tem como escapar \\
\hline Pensei numa estratégia, & Alunos desanimados & "Anjos" que desceram & Faça a sua parte \\
\hline $\begin{array}{l}\text { Que pudesse animá-los } \\
\text { Oue pudesse envolvê-los }\end{array}$ & As familias apavoradas & Do céu & Que eu faço a minha \\
\hline $\begin{array}{l}\text { Que pudesse envolvê-los } \\
\text { Há!... Uma produção coletiva }\end{array}$ & 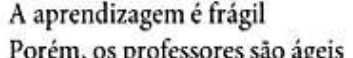 & Para salvar os irmàos. & Nào pense que é \\
\hline Para ficar bem ativos. & O Fernando na gramática & $\begin{array}{l}\text { Para eles não existem casos perdidos, } \\
\text { E sim, obstáculos pra serem vencidos }\end{array}$ & Uma gripezinha! \\
\hline Foi uma revolução & A Flávia nas oficinas & Mesmo nas dificuldades & O mal é contagioso, \\
\hline A maior animação & Na Redação, Hildalene & Não desistem de ninguém & Mas o bem é contagiante \\
\hline No grupo do WhatsApp & Na literatura, o Romero & É por isso que merecem & Lá na frente a gente se encontra \\
\hline Cada um criava seus versos & A eles, nosso abraço sincero & Serem retribuidos & É só tomar cuidado \\
\hline E o outro continuava & & De pé, com nossos aplausos. & E seguir adiante. \\
\hline
\end{tabular}

Fonte: SEDUC Piauí (2020)

O cordel foi instrumento de outros trabalhos voltados à conscientização na pandemia. $\mathrm{O}$ SESC Ceará (2020) elaborou "O coronavírus", livreto de cordel produzido pelo conhecido Palhaço Formiguinha. A Biblioteca Histórica do Colégio Pedro II no Rio de Janeiro lançou um projeto para criação de cordéis que irão compor seu acervo "Projeto Cordel do Isolamento: a pandemia contada em forma de literatura de cordel", objetivando registrar as experiências dos alunos e bibliotecários durante a pandemia e que serão publicados em forma de e-book e servirão para a construção da memória histórica do colégio sobre o período (CORBÔ, 2020).

Já em Pio IX, no Piauí, cidade sem infraestrutura para tratar casos graves de Covid-19, a agente de saúde Maria Marilene do Monte Carvalho se utilizou do cordel para ensinar sobre proteção contra o vírus ao perceber que parte da população não conseguia compreender as informações repassadas pela mídia. Ela produziu os cordéis "\#FiqueEmCasa" e "Faça sua Parte" e os apresentou em formato impresso e em vídeo. Seu projeto foi reconhecido pela Organização Pan-Americana da Saúde (OPAS), braço da Organização Mundial da Saúde para 
as Américas, e concorre a um prêmio pela iniciativa inovadora para contenção ao novo coronavírus (MAIA; XAVIER, 2020), uma vez que, o Estado, suas lideranças e a diplomacia médica internacional constituem importante papel na identificação e apoio às micro ações voltadas à contenção do vírus (LUIGI; SENHORAS, 2020).

A Organização das Nações Unidas (ONU BRASIL, 2020) também produziu uma série de vídeos em formato de cordel no Youtube, com conscientização e orientações a respeito da pandemia. Vale ressaltar que a ONU já publicou uma carta produzida em cordel, tida como "a carta mais importante da história da humanidade e a das Nações Unidas", escrita por Tião Simpatia em 2019 e intitulada Carta das Nações Unidas (ALCE, 2019, p. 1).

Durante a pandemia, percebe-se que a produção virtual foi relevante para a disseminação da informação, em especial, referente ao coronavírus. Para Montenegro e Ferreira (2020, p. 2) a internet se tornou um lugar em que produções artísticas e literárias podem ser armazenadas e o nordestino, "que possui a migração como um marco histórico relevante, hoje se permite migrar para os ambientes virtuais e apresentar a sua cultura por meio de diversos canais de comunicação".

\section{Metodologia}

Este estudo tem caráter exploratório e descritivo, uma vez que, segundo Prodanov e Freitas (2013), a pesquisa exploratória proporciona informações sobre o objeto investigado facilitando a definição e delineamento de suas bases e desenvolvimento do tema proposto por meio de levantamento bibliográfico. Já a pesquisa descritiva, segundo os autores, "visa a descrever as características de determinada população ou fenômeno ou o estabelecimento de relações entre variáveis" (PRODANOV; FREITAS, 2013, p. 52), com o intuito de descobrir suas características, causas e relações com outros fatos.

A pesquisa é desenvolvida com uma abordagem qualitativa, por meio de um estudo de caso que, segundo Gil (2010), é uma modalidade de pesquisa que consiste no estudo profundo e exaustivo do objeto investigado, de forma que seja possível tornar conhecidos seus aspectos, por meio da exploração de situações reais e descrição do contexto em que se insere. Para Yin (2005), esse é o tipo de pesquisa ideal quando não se tem controle sobre o que acontece, cujo foco, está em fenômenos contemporâneos, como é o caso deste estudo. 
O caso estudado é o da cordelista sergipana Cláudia Emilly Silva Barreto que administra a conta do perfil voltado à divulgação de seus cordéis nas mídias digitais, chamado de 'Um Amontoado de Versos'. A escolha de um único caso para o estudo não tem a intenção de criar generalizações que, conforme Stake (2000), pode acabar desviando a atenção de questões fundamentais que podem ser tratadas, e de ser também, um ponto de partida para que pesquisas posteriores possam ser desenvolvidas, afinal, a intenção do estudo de caso para Platt (2007), é a de representar o caso, "e não o mundo", uma vez que o que se busca é adequar o fenômeno e os pressupostos estabelecidos para que haja validação, deixando em segundo plano as preocupações acerca do número de casos estudados para possível generalização.

A coleta dos dados foi realizada a partir de entrevista semiestruturada realizada de forma online por meio da ferramenta Google Meet ${ }^{\circledR}$ e teve duração de $1 \mathrm{~h} 35 \mathrm{~min}$. As gravações em áudio e vídeo foram transcritas e seguidas da etapa da Análise de Conteúdo de Bardin (2016), o que possibilitou a organização das ideias, a pré-análise dos dados, e a escolha das categorias a serem analisadas. A técnica de Análise de Conteúdo é utilizada para análise das informações recolhidas como meio de compreensão crítica do sentido que existe por trás do conteúdo das mensagens conseguidas. Após interpretadas, as informações são organizadas segundo critérios estabelecidos, para que inferências sobre as mensagens possam ser feitas.

Bardin (2016) estabelece as seguintes etapas para a análise de conteúdo que garantem o rigor metodológico e a validade dos dados: a) pré-análise; b) exploração do material, categorização ou codificação; c) tratamentos dos resultados, inferência e interpretação. Conforme Bardin (2004), a pré-análise permitiu observar as ideias preestabelecidas no estudo, permitindo sistematizar as próximas etapas da análise. $\mathrm{Na}$ segunda fase, o material foi explorado com profundidade, a fim de que fosse possível o desmembramento e agrupamento de ideias semelhantes ou que se repetissem no conteúdo das falas da entrevistada. Feito isto, foi possível perceber que as ideias organizadas correspondiam ao que foi estabelecido nos objetivos deste estudo. Sendo assim, as categorias que haviam sido definidas a priori (BARDIN, 2016) foram confirmadas, da seguinte forma:

1) Motivação para atuar no meio digital durante a pandemia;

2) Estratégias de marketing digital durante a pandemia;

3) Influência das mídias digitais no trabalho;

4) Principais dificuldades no contexto das mídias. 
Feita a categorização, partiu-se para a última etapa da Análise de Conteúdo que inclui tratamento do resultado, inferência e interpretação. Nesse sentido, foi realizada a triangulação dos resultados apresentados com outros estudos que têm semelhança em seu conteúdo, conseguindo-se, assim, a validação do método utilizado.

\section{Resultados e discussões}

A cordelista Cláudia Emilly Silva Barreto utiliza seu perfil "Um amontoado de versos" nas mídias digitais que se estabelece na rede da seguinte forma: o perfil do Instagram conta com quase 3 mil seguidores e 113 publicações, desde sua criação em 2017. No Youtube, segue com cerca de mil inscritos, tendo publicado 70 vídeos desde fevereiro de 2020, quando decidiu criar o canal na plataforma (momento que coincide com os decretos de isolamento social em decorrência do Covid-19), com mais de 21 mil visualizações até a finalização deste estudo.

$\mathrm{Na}$ plataforma de publicação de livros digitais Wattpad, a autora possui 4 obras lançadas, sendo duas de cordel e duas coleções de poesias, que juntas obtiveram uma média de 14 mil visualizações de usuários. O WhatsApp se tornou uma plataforma de disseminação do conteúdo que publica nas demais plataformas e o Facebook segue com seus 287 seguidores, com a predominância de público mais velho.

Vale a pena destacar, que a produção do cordel em folheto, antes elaborada manualmente como suporte à poesia cantada, passava por todo um processo técnico de editorial possibilitado a partir do advento da imprensa no Brasil. Conforme os poetas se aventuravam na edição e impressão dos folhetos, acontecia todo o processo de elaboração do texto, das ilustrações em xilogravuras, até que fosse enviado a um revisor e finalmente, a uma editora para impressão (IPHAN, 2018). Um sistema editorial complexo que ainda existe nos dias de hoje, mas que se rende, cada dia mais, à produção e divulgação digital. A exemplo da cordelista Emilly Barreto, ela mesma se encarrega do processo de edição dos cordéis e tudo acontece a partir de recursos online como aplicativos de edição de imagem e texto.

Conforme a metodologia de Bardin (2016), foi feita a triangulação dos resultados com outras pesquisas existentes, a partir de categorias escolhidas a priori, sintetizadas pelos objetivos da própria pesquisa. No que diz respeito à primeira categoria "Motivação para atuar no meio digital durante a pandemia", a cordelista afirma (BARRETO, 2021):

InCID: R. Ci. Inf. e Doc., Ribeirão Preto, v. 12, n. 2, p. 239-260, set. 2021./fev. 2022. 
Eu sempre quis postar mais, interagir mais, mas talvez faltasse tempo, entre todas as outras coisas que eu tava inserida [...] Daí, no período da pandemia me sobrou mais tempo, pra explorar ainda mais isso que já tinha começado. Mas não deixa de ser uma reinvenção (grifo nosso).

Por conta da pandemia eu fiquei muito tempo em casa e eu acabei criando o meu canal onde eu trago uma abordagem cultural, artística e literária.

Percebe-se que a cordelista foi motivada a investir nas mídias digitais diante do estado de quarentena decorrente da pandemia. O primeiro caso de infecção pelo vírus no Brasil foi registrado em fevereiro de 2020 e, desde os decretos iniciais de calamidade pública estabelecidos pelo governo do estado de Sergipe, a cordelista tem intensificado sua atuação nas mídias sociais, já que, tem lhe sobrado mais tempo para dedicação a esta tarefa:

\begin{abstract}
Agora na pandemia todo mundo se rendeu e viu que as redes sociais só têm a acrescentar, porque lá, a gente já coloca uma imagem ilustrativa, o texto escrito ou só a voz, declamado [...] pode colocar em vídeo [...] Então, é uma variedade imensa que as redes sociais oferecem, além de poder ter diversas formas de se expressar, tem uma maior possibilidade de o seu conteúdo chegar mais longe, chegar em pessoas que você nunca viu, chegar em outro país, em outros Estados, em outras cidades, alcançar mais pessoas e, consequentemente, propagar mais a cultura, compartilhar mais pras outras pessoas conhecerem. Sou $100 \%$ a favor da divulgação virtual. [...] Eu acho que tudo se modernizou e o cordel também precisou se modernizar (BARRETO, 2021).
\end{abstract}

Como previu Pierre Levy (1999, p. 233), os modos de expressão para comunicação no ciberespaço evoluíram e chegaram a variadas formas, conforme as utilizadas pela cordelista hoje, do "hipertexto até hiperdocumentos multimodais ou filmes em vídeo digital. [...] novas formas de escrever imagens, novas retóricas da interatividade". Para ele, o "centro de gravidade informacional" se voltaria para aqueles que buscam pela informação, favorecendo a conexão em forma de comunidades virtuais.

Assim, segundo Carneiro (2020), o distanciamento social durante a pandemia mudou o modo como as pessoas interagem, tornando as mídias sociais, um canal de comunicação nunca antes tão utilizado. Esse aumento se deve à necessidade de se reinventar diante deste cenário, seja por questões pessoais ou profissionais. Carneiro (2020) afirma que "Argentina, Brasil, Chile e Paraguai são os países com o maior percentual de mudança no número de publicações e interações em mídias sociais multiplataforma registradas em março de 2020, em comparação com o ano anterior".

Os dados indicam, ainda, que o maior engajamento tem sido observado na rede social Instagram, com aumento de $100 \%$ em interações em relação a março de 2019. O Instagram tem sido o principal canal online de comunicação utilizado pela cordelista, conforme sua posição diante da segunda categoria "Estratégias de marketing digital durante a pandemia". No entanto, a entrevistada afirma que ainda não tem acompanhamento de um profissional de marketing ou 
de comunicação em suas produções nas mídias digitais: "É apenas eu”. Ela prossegue (BARRETO, 2021):

\footnotetext{
Eu não penso ainda de forma tão estrategista ou, até não consigo, ainda, mas preciso. E eu nunca cheguei a pagar os anúncios do Instagram, nem do Google.

[...] assim, eu peço pros meus amigos compartilharem. Eu acho que quando há essa rede de compartilhamento, aumenta o número de seguidores, de inscritos. Eu até disse: 'todos os meus amigos já estão inscritos no meu canal' e agora eu preciso chegar aos amigos dos meus amigos'.
}

Sendo assim, a realidade imposta pelo vírus e o melhor acesso à internet permitiram que algumas alternativas digitais fossem utilizadas (MARCELINO; MIYAJI; REZENDE, 2020) de forma ampliada nas ações de comunicação da cordelista, necessitando que a maneira de se relacionar fosse melhor desenvolvida nesses canais para que o público fosse mantido e novos fossem conquistados. Dessa forma, ela apresenta suas principais mídias digitais e a forma como as utiliza para se comunicar com seu público. Ela deposita no Instagram sua maior dedicação para publicação e interação com o público, mas não deixa de se utilizar de outras mídias que também são muito utilizadas pelos seus seguidores, de forma que consegue fazer conexão entre todas elas para melhorar a eficiência de seus meios de comunicação virtuais. Ela complementa (BARRETO, 2021):

[...] o Instagram é a mais utilizada...

[...] então, eu vejo no Instagram, uma forma de crescer, uma oportunidade de mostrar minhas produções, de uma forma diferente também, pra um público jovem.

[...] eu entendo tudo como interligado. Uso o virtual pra ouvir o meu programa na rádio, depois eu pego o áudio da rádio e posto no Youtube. Tem mais interação do público. E no Youtube é o que tem mais dificuldade até agora.

Eu utilizo 5 plataformas que são: Instagram, Facebook, Wattpad, Youtube e Whatsapp. [...] o WhatsApp é onde eu faço a divulgação de todas as outras. Eu utilizo todos os grupos que estou inserida e os contatos pra convidar a galera pra ir ver as produções nos outros. Mas também público no meu status no WhatsApp.

Eu também participo através de uma página no Facebook... transmito uma espécie de jornal online que faço com um amigo [...], nós transmitimos o jornal semanalmente, comentando sobre os principais fatos que acontecem na nossa cidade, e eu começo esse jornal declamando sempre um cordel, finalizo também declamando um cordel.

Essas plataformas de comunicação e marketing têm a potencialidade de agregar valor e dar visibilidade no meio de atuação, mas, para isso, é imprescindível que haja uma estratégia de marketing digital para o estabelecimento de presença no ciberespaço, mediante planejamento, estudos de mercado e do comportamento do público-alvo. Dessa forma, é possível engajar o público de forma mais assertiva. O cordel tem sido apresentado pela cordelista também por meio de vídeos, e ela percebe que o interesse e a interação do público são maiores do que quando há publicações no formato escrito. 
Além disso, a utilização do Instagram como principal meio de comunicação com o público tem sido uma aposta assertiva da cordelista, já que, segundo Siqueira (2020), a mídia superou em 20 vezes o número de interações do Facebook e, ainda que seu número de usuários seja menor que este, os investimentos em anúncios aumentaram em 40\%. Assim, as mídias sociais têm influenciado o trabalho da cordelista, conforme reforçado na terceira categoria "Influência das mídias digitais no trabalho" (BARRETO, 2021):

O interesse e a interação do público hoje é maior. [...] quando é passado por meio de vídeo, eu sinto que ele tem aceitação maior do que quando é escrito, e as pessoas interagem mais. Acho que tá sendo mais aceito. Até o jovem, que tem esse preconceito todo de tipo, "ah, coisa de velho", vê outra pessoa jovem declamando, vê que não tá tão distante de um $R E P$, que o $R E P$, ele é composto por rimas e é bem parecido com a questão estrutural do cordel, vê que não é algo ultrapassado, vê que é algo ali, atual.

Agora na pandemia, participei de diversas lives como telespectadora, aprendendo com meus colegas, conhecendo outros escritores e também pude promover lives contando minha experiência e assim, inspirando outros jovens. Também pude declamar... e eu acho surpreendente esse fato de sua mensagem chegar a pessoas que você nunca vai conhecer, isso vai deixando a produção de certa forma imortalizada. Pra você ser imortalizado você precisava estar nos livros, e agora você também pode deixar o seu registro ali de uma forma virtual.

O cordel passou a ser mais acessível, no sentido de não haver a dependência da mostra do meio físico, de uma feira, bienal etc. Tem acesso a um conteúdo gratuito. Muitos e-books gratuitos de cordelistas renomados, muitos vídeos disponíveis, então, o acesso é muito mais facilitado, democrático.

O que Lévy (1999, p. 233) chamou de "novas mídias", favoreceriam, segundo ele, "o fim do monopólio da expressão pública" e permitiriam que os indivíduos produzissem e disponibilizassem conteúdos diversos em variados modos de expressão de baixo custo, a nível nacional e internacional. Durante a pandemia, a cordelista em questão intensificou a utilização do ciberespaço e percebeu que há várias mídias digitais com diferentes funcionalidades e finalidades que a ajudaram na aproximação com o público. Por meio dessas plataformas, ela conseguiu firmar parcerias e ser vista por outros profissionais afins, uma vez que, segundo Lévy (1999), é possível encontrar mais facilmente por pessoas que compartilham do mesmo tema de interesse e se situam no mesmo espaço de competência.

Dessa forma, as TIC permitiram uma inédita melhoria na interação entre os indivíduos conectados à internet, sendo capazes de influenciar seus comportamentos, aproximando-os a partir de qualquer lugar do mundo. Assim, os profissionais ganham uma nova forma de dar visibilidade à sua produção e um meio pelo qual os criadores de conteúdo oferecem seus serviços no mercado, utilizando-se de ações de propaganda e marketing. É possível a esses profissionais, ainda, monitorar e avaliar em seus perfis a recepção do conteúdo por meio de recursos como "curtir" e "reagir" e dos comentários e compartilhamentos, constituindo o modo 
mais célere de dar feedback no espaço midiático e, também, de geração de valor (ARAÚJO; ZILBER; 2016; OLIVEIRA, 2018).

No contexto pandêmico, a cultura popular tem enfrentado dificuldades que vão além daquelas de costume, em detrimento de sua preservação e disseminação, tendo agora algumas pedras a mais à vista. É sobretudo na "celebração do encontro, nas festas, nas cirandas, nas rodas de samba, nos terreiros" que a cultura tradicional se estabelece (CAVALCANTE, 2020). No entanto, como expressado pela cordelista, o ciberespaço expandiu o próprio espaço de atuação do artista, por meio de eventos online e conteúdos que não seriam possíveis caso o contato permanecesse totalmente presencial. Conforme ela expressa: "Eu tive até mais oportunidade pra dar entrevistas em tipo, internacionais, que eu não teria essa oportunidade de forma presencial" (BARRETO, 2021).

No que diz respeito à última categoria "Principais dificuldades no contexto das mídias", a entrevistada retoma o fator tempo, citado na resposta à primeira questão. Ela afirma: “[...] minha dificuldade sempre foi tempo. Porque eu não podia gastar todo meu tempo em algo que não me dava retorno financeiro" (BARRETO, 2021). Outro ponto crucial citado relaciona-se às dificuldades com questões técnicas, que influenciam na produção de conteúdo em seu perfil, onde equipamentos como notebook, câmera e microfone eficientes influenciam na qualidade de suas publicações em imagem e vídeo, assim como na opinião de seus seguidores.

A questão da estrutura [...] até hoje, não tô com notebook, ai dificulta trabalhar pelo celular. Meu equipamento pro meu canal, pros meus vídeos todos, é um celular e um tripé. A gente sabe que quanto mais equipamentos, melhora a qualidade dos vídeos, e até o povo cobra, 'melhore sua iluminação, sua câmera... principalmente o áudio'. O povo cobra, 'melhore nisso e naquilo'. Mas ainda, a gente tem essas deficiências.

Lévy (1999) afirma que, para atuar no meio digital, é imprescindível dispor de infraestrutura material, mas, além disso, é necessário o desenvolvimento de algumas competências. Sendo assim, não adiantaria à cordelista investir em equipamentos se não estivesse capacitada para atuação no meio digital, uma vez que, segundo a OECD (2020, p. 150) “o investimento em conhecimento é essencial para [...] adaptação à transformação digital”. Dessa forma, o êxito virá, não só por capacitações voltadas ao uso de equipamentos necessários à operacionalização do trabalho, mas por meio também de outras, voltadas à gestão de negócios e gestão de mídias sociais digitais: 
[...] tenho uma amiga poetisa que diz que o Instagram acaba com a autoestima poética dela. Porque assim... a gente sabe que a audiência que um perfil literário vai ter não é a mesma que um perfil de uma blogueira de moda, e principalmente em uma rede social como o Instagram, que se sabe, ele tem a questão dos algoritmos... eu não entendo muito bem, mas eu sei que ele dá as preferências a alguns tipos de conteúdo. E muitas das vezes o poeta se sente com a autoestima abalada. Alguns... a mim não se aplica. Mas falando com uma visão geral, se sente um pouco mal. No Instagram a gente meio que se compara, o engajamento no nosso conteúdo com o engajamento em outros conteúdos e isso gera um pouco de tristeza (grifo nosso).

Além de dificuldades materiais, estão aquelas relacionadas à autoestima da cordelista. Ela comenta a respeito de sua amiga poetisa que afirma que "o Instagram acaba com a autoestima poética", uma vez que é inevitável fazer comparações de métricas entre perfis. No entanto, a cordelista afirma que de modo geral, há um sentimento de desconforto ao relacionar o desempenho do próprio perfil com outros, comportamento esperado aos usuários das mídias sociais que, segundo Odriozola (2020, p. 1) "são desenhadas para jogar com nossa vulnerabilidade nos ativando gatilhos de insatisfação e insegurança". Assim, o que se tornou um recurso importante para a manutenção dos relacionamentos e afetos durante o enfrentamento das restrições na da pandemia, influenciou, também, na autoestima dos usuários de forma negativa, pelas comparações feitas entre perfis e postagens de sucesso, intensificando sentimento de insegurança, frustração, impotência e outros (DAMACENO, 2020).

\section{Considerações finais}

Ao final desse estudo, percebe-se a presença marcante da cordelista Cláudia Emilly Silva Barreto nas principais mídias digitais e da influência da pandemia em seu trabalho. Sua principal motivação para atuar no meio digital, ou para atuar de forma mais intensa, é a maior disponibilidade de tempo em decorrência da pandemia, que fez com que as pessoas ficassem mais tempo conectadas à rede e tivessem acesso a seu conteúdo. Com isso, foi possível que sua arte chegasse a um número maior de pessoas e que elas interagissem mais nas diversas plataformas digitais em variadas formas de apresentação do conteúdo.

Diante disso, e sem a dependência do meio físico, o cordel produzido localmente passou a ser mais acessível e apresentado não só nacionalmente, mas também, em eventos internacionais. Essa difusão dos poemas não teria sido tão fácil sem que esses dispositivos tecnológicos tivessem extrapolado as fronteiras nacionais.

No que se refere às estratégias de marketing digital, a mídia mais utilizada e que lhe proporciona mais engajamento com o público é o Instagram. Ela se utiliza, ainda, de outras 
redes sociais acessadas no país e no mundo, como forma de ampliar sua presença digital. A cordelista Cláudia Emilly demonstra interesse em tratar seu negócio de forma mais estratégica, mas ainda não tem acompanhamento de um profissional de marketing digital ou de comunicação, nem participou de treinamentos na área. Isso indica que a mesma ainda necessita desenvolver melhor tais competências, caso queira ganhar mais notoriedade no ciberespaço.

Além disso, dentre suas principais dificuldades com as mídias, estão a falta de equipamentos adequados para produções de qualidade e disponibilidade de tempo para promover o perfil na internet. É nesse momento que, não só a disponibilidade de infraestrutura para desenvolvimento dos trabalhos é importante, mas também capacitação para a utilização desses recursos. Outra dificuldade é a comparação inevitável do trabalho publicado com o trabalho de outros perfis que, não raramente, causa sentimentos de baixa autoestima.

A questão que fica é, se após passado o estado emergente de distanciamento social, a cordelista estará mais preparada, com capacitações, disponibilidade de tempo e infraestrutura para dar continuidade a seus trabalhos nas mídias digitais de forma estratégica. Ademais, a atuação dela representa importante papel na disseminação da cultura popular do Estado de Sergipe, ainda que com limitações, e as mídias digitais têm ajudado a atravessar as fronteiras locais levando a literatura de cordel a mais pessoas e espaços, onde suas obras têm a chance de entreter e, principalmente, munir o público de reflexões sociais críticas frente à luta por uma sociedade mais justa, garantindo seu reconhecimento, a manutenção da memória e o fortalecimento dessa arte popular tão importante para a nação.

Por fim, cabe ressaltar a representatividade da posição da cordelista como uma das mais notórias artistas do Estado de Sergipe. Sua figura feminina, em meio a um espaço majoritariamente masculino, que durante todo um século subestimou a mulher, agora se sobressai e serve de inspiração para outras cordelistas, que têm no ciberespaço uma maior democratização em relação à sua expressividade por meio da arte e da exposição do seu pensamento. 


\section{Referências}

ALBUQUERQUE, G. A. et al. Educação em saúde e prevenção ao novo coronavírus por meio da literatura de cordel. Asas da Palavra, v. 17, n. 2, jul./dez. 2020. Disponível em: http://revistas.unama.br/index.php/asasdapalavra/article/view/2333. Acesso em: 12 dez. 2020.

ALCE. Carta das Nações Unidas em cordel. 2019. Disponível em: http://bit.ly/govliteratura-de-cordel. Acesso em: 21 jan. 2021.

ARAÚJO, J. B.; ZILBER, S. N. Que fatores levam as empresas a adotar mídias sociais em seus processos: proposta e teste de um modelo de medição. Brazilian Business Review, Vitória, v. 13, n. 6, p. 270-303, nov./dez. 2016. Disponível em: https://bit.ly/3aldrFU. Acesso em: 14 jan. 2021.

BARDIN, L. Análise de conteúdo. Lisboa: Edições 70, 2004.

BARDIN, L. Análise de Conteúdo. São Paulo: Edições 70, 2016.

BARRETO, C. E. S. Entrevista concedida em 06 jan. de 2021.

BETELLA, G. K., CAÇÃO, B. L. F. S. Cultura e relações de reciprocidade: a literatura de cordel em diferentes contextos. Revista Leia Escola, v. 16, n. 2, 2016. Disponível em: http://revistas.ufcg.edu.br/ch/index.php/Leia/article/view/711. Acesso em: 25 jan. 2021.

BRASILEIRO, O. J.; SILVEIRA, R. C. Literatura e oralidade no cordel: identidade e memória cultural nordestina. Nau Literária: crítica e teoria de literatura, Porto Alegre, v. 09, n. 01 - Dossiê: voz e interculturalidade, jan./jun. 2013. Disponível em: https://doi.org/10.22456/1981-4526.43381. Acesso em: 24 dez. 2020.

CARNEIRO, E. Os impactos nas redes sociais devido à pandemia. Ponto ISP, 13 maio 2020. Disponível em: https://bit.ly/3uUNmVS. Acesso em: 15 jan. 2021.

CASTELLS, M. A era da informação: economia, sociedade e cultura. São Paulo: Paz e Terra, 2000. (A Sociedade em rede, v. 1).

CAVALCANTE, G. S. Cultura popular na pandemia. Revista Raiz, 13. ago. 2020. Disponível em: http://raiz.art.br/2020/08/13/cultura-popular-na-pandemia-2/. Acesso em: 14 jan. 2021.

CORBÔ, P. A. B. Projeto \#bibliotecaIndica: cordel do isolamento. Colégio Dom Pedro II, 2020. Disponível em: https://www.cp2.g12.br/blog/humaita1/2020/09/10/projetobibliotecaindica-cordel-do-isolamento/\#comment-551. Acesso em: 20 jan. 2021.

COSTA, G. Professora e alunos do Piauí criam cordel sobre desafios da educação na pandemia: 'sonhos adiados'. 30 ago. 2020. Disponível em: https://glo.bo/3e89BRn. Acesso em: 20 jan. 2021.

DAMACENO, T. W. A autoestima e as redes sociais na quarentena. 23 jun. 2020. Disponível em: https://spsicologos.com/2020/06/23/a/. Acesso em: 25 jan. 2021. 
DESTRI, L. Uma trama de cordéis. Revista Pesquisa Fapesp, Edição 275, jan. 2019. Disponível em: http://bit.ly/fapespumatramadecordeis. Acesso em: 12 jan. 2021.

FONSECA, M. G. C. Poesia de cordel no Facebook: as potencialidades do suporte no caso do cordel "Política x Amizade". RuMoRes, São Paulo, v. 10, n. 19, p. 138-157, jun. 2016.

FREITAS, L. L.; SOUZA, T. B. Literatura de cordel no fio da rede: o cibertexto poético [...] digital. Scripta Alummi, Curitiba, v. 23, n. 2, p. 158-177, jul./dez. 2020. Disponível em: http://bit.ly/uniandradebrrevistauniandrade. Acesso em: 15 jan. 2021.

GIL, A. C. Como elaborar projetos de pesquisa. 5. ed. São Paulo: Atlas, 2010.

IPHAN. Literatura de cordel: dossiê de registro. Brasília, 2018. Disponível em: http://portal.iphan.gov.br/uploads/ckfinder/arquivos/Dossie_Descritivo(1).pdf. Acesso em: 22 jul. 2021.

IUMATTI, P. T. Cordel e patrimônio. Revista do Instituto de Estudos Brasileiros, Brasil, n. 72, p. 221-224, abr. 2019. Disponível em: http://bit.ly/gtrcvop. Acesso em: 24 dez. 2020.

JARES, M. Resistência e identidade cultural na literatura de cordel. 2010. 14f. Artigo (Especialista em mídia, informação e cultura) - Centro de Estudos Latino-Americanos sobre Cultura e Comunicação, ECA, USP, 2010. Disponível em: http://celacc.eca.usp.br/?q=ptbr/tcc_celacc/resistencia-identidade-cultural-literatura-cordel. Acesso em: 23 dez. 2020.

JENKINS, H. Cultura da convergência. 2. ed. São Paulo: Aleph, 2009. 428p.

LEMAIRE, R. O cordel como fenômeno multicultural: fonte de informação e conhecimento, folclore ou literatura? Universidade Federal do Ceará, [201-].

LEVY, P. Cibercultura. São Paulo: Editora 34, 1999.

LIMA, S. T. O Fantástico como denúncia do real: uma abordagem no cordel nordestino. Revista Entrelaces, v. 8, n. 20, abr.jun. 2020. Disponível em: http://www.repositorio.ufc.br/handle/riufc/53341. Acesso em: 24 dez. 2020.

LUIGI, R.; SENHORAS, E. M. O novo coronavírus e a importância das organizações internacionais. Nexo Jornal, 2020.

MAIA, D.; XAVIER, K. Agente de saúde usa literatura de cordel para ensinar como moradores devem se proteger do coronavírus. Folha de São Paulo, São Paulo, 25 out. 2020. Disponível em: http://bit.ly/uolobrasildasvariaspandemias. Acesso em: 20 jan. 2021.

MARCELINO, J. A.; MIYAJI, M. REZENDE, A. A. A reinvenção das vendas: as estratégias das empresas brasileiras para gerar receitas na pandemia de Covid-19. Revista Boca, Boa Vista, ano II, v. 2, n. 6, 2020. Disponível em: http://bit.ly/iguvytf. Acesso em: 20 jan. 2021.

MARIANO, M. R. C. P.; SANTOS, F. A. O lugar do cordel no livro didático: reflexões e análise. Interdisciplinar, São Cristóvão, v. 31, p. 59-72, jan./jun. 2019. Disponível em: https://doi.org/10.47250/intrell.v31i1.11487. Acesso em: 24 dez. 2020. 
MELO, R. A. Do rapa ao registro: a literatura de cordel como patrimônio cultural do Brasil. Revista do Instituto de Estudos Brasileiros, São Paulo, n. 72, p. 245-261, 2019. DOI https://doi.org/10.11606/issn.2316-901X.v0i72p245-261. Disponível em: https://www.revistas.usp.br/rieb/article/view/157060. Acesso em: 21 dez. 2020.

MONTENEGRO, T. M.; FERREIRA, R. S. S. O nordestino migrante em território virtual: possibilidades de alteridade pela presença da literatura de cordel nas plataformas digitais.

Darandina Revisteletrônica, Juiz de Fora, v. 13, n, 2, 2020. Disponível em: https://www.ufjf.br/darandina/files/2020/12/Artigo-2-O-nordestino-migrante.pdf. Acesso em: 20 dez. 2020.

NASCIMENTO, J. B. D.; SANTOS, F. P. A literatura de cordel como fonte de informação: um olhar historiográfico e conceitual. Folha de Rosto, Juzeiro do Norte, v. 1, n. 1, p. 101112, jul. 2015. Disponível em: http://bit.ly/folhaderostoFontedeinformação. Acesso em: 24 dez. 2020.

NOBRE, F. A. S. Um catálogo de folhetos de cordel científicos e uma sequência de ensino. Universidade Regional do Cariri - Université de Poitiers. 2018.

ODRIOZOLA, M. Vício em redes sociais dispara na pandemia, mas há como recuperar o controle e se desintoxicar. El País, 12 out. 2020. Disponível em: http://bit.ly/elpais Vícioemredessociais. Acesso em: 15 jan. 2021.

OECD. A caminho da era digital no Brasil, OECD Publishing: Paris, 2020. Disponível em: https://doi.org/10.1787/45a84b29-pt. Acesso em: 25 jan. 2021.

OLIVEIRA, R. R. Mídias digitais: implicações sobre o processo democrático. Rev. Cadernos de Campo, Araraquara, n. 25, p. 229-244, jul./dez. 2018. Disponível em: https://periodicos.fclar.unesp.br/cadernos/article/view/11556/8135. Acesso em: 14 jan. 2021.

ONU BRASIL. Cordel da informação: COVID-19. 01 jun. 2020. Duração 1:21min. Youtube. Disponível em: http://bit.ly/cordeldainformacao. Acesso em: 21 jan. 2021.

PAZ, J. F.; BEZERRA JÚNIOR, W. B. Cordel: literatura que transforma o sujeito, o lugar e o seu povo. Revista Interdisciplinar em Estudos de Linguagem, São Paulo, v. 2 n. 2, 2020. Disponível em: https://doi.org/10.29327/2.1373.2.2-16. Acesso em: 24 dez. 2020.

PLATT, J. Estudo de caso. In: OUTHWAITE, W.; TURNER, S. The Sage handbook of social science methodology. London: Sage, 2007.

PORFÍRIO, F. Cultura de massa. Brasil Escola. 2021. Disponível em: http://bit.ly/uolculturademassa. Acesso em: 30 jan. 2021.

PRODANOV, C. C.; FREITAS E. C. Metodologia do trabalho científico: métodos e técnicas da pesquisa e do trabalho acadêmico. 2. ed. Novo Hamburgo: Feevale, 2013.

QUEIROZ, D. A. Mulheres cordelistas: percepções do universo feminino na literatura de cordel. 2006. 121 f. Dissertação (Mestrado em Letras) - Programa de Pós-Graduação em Letras - Estudos Literários, Faculdade de Letras da UFMG, Belo Horizonte, 2006. Disponível 
em: https://repositorio.ufmg.br/bitstream/1843/ALDR-6WEK7J/1/disserta_o.pdf. Acesso em: 22 jul. 2021.

RESENDE, V. M. A relação entre literatura de cordel e mídia: uma reflexão acerca das implicações para o gênero. Cadernos de Linguagem e Sociedade, 8, 2006/7. Disponível em: file:///C:/Users/User/Dropbox/PPGCI\%202021.1/Artigo\%20Cordel/INCID\%20Avalia\%C3\% A7\%C3\%A3o/Autor\%20que\%20falta/Resende.pdf. Acesso em: 25 jan. 2021.

SANTAELLA, L. Novos desafios da comunicação. Lumina: Facom/UFJF, Juiz de Fora, v. 4, n. 1, p.1-10, jan/jun 2001. Disponível em: https://www.ufjf.br/facom/files/2013/03/R5Lucia.pdf. Acesso em: 25 jan. 2021.

SANTOS, F. P. Poética das vozes e da memória. In.: MENDES, S. (Org.). Cordel nas gerais: oralidade, mídia e produção de sentido. Fortaleza: Expressão Gráfica, 2010. p. 43-63.

SEDUC PIAUÍ. Nosso cordel. Unidade Escolar Dom Joaquim Rufino do Rêgo. 29 p. 2020. Disponível em: http://bit.ly/nossocordel. Acesso em: 20 jan. 2021.

SESC CEARÁ. O coronavírus. 2020. Disponível em: http://bit.ly/ocoronavirus. Acesso em: 20 jan. 2021.

SIQUEIRA, T. Instagram supera Facebook em número de interações pela primeira vez. TechTudo, 04 mar. 2020. Disponível em: http://bit.ly/mnfjenf. Acesso em: 15 jan. 2021.

STAKE, R. O método de estudo de caso na investigação social. In: DENZIN, N. K.; YVONA, L. S. The American tradition in qualitative research. Thousand Oaks, California: Sage, 2000. vol. II.

TRIGUEIRO, O. M. A espetacularização das culturas populares ou produtos culturais folkmidiáticos. In: CONGRESSO BRASILEIRO DE FOLCLORE. Metodologia da pesquisa em folclore, preservação dos bens da cultura imaterial, 11., 2004, Goiânia. Anais [...] Goiânia: Kelps, 2004. Disponível em: http://bit.ly/folkmidiaticos. Acesso em: 29 jan. 2021.

VALENTIM, M. (Org.). Gestão, mediação e uso da informação. São Paulo: Editora UNESP, 2010. 390 p.

VERDÉLIO, A. OCDE apresenta relatórios sobre era digital e telecomunicações no país. 2020. Disponível em: http://bit.ly/relatorioeradigital. Acesso em: 15 jan. 2021.

YIN, R. K. Estudo de caso: planejamento e métodos. 3. ed. Porto Alegre: Bookman, 2005.

ZUMTHOR, P. A permanência da voz. O Correio, Rio de Janeiro, ano 13, n. 10, p. 04-08, out. 1985 . 